\title{
THE IMPACT-FACTOR NEUROSIS, COMPETITIVENESS NECESSITY AND INATTENTION CAN CAUSE IRREPARABLE DAMAGE...
}

About ten years ago, the valid paradigm for worldwide researchers was: publish or perish. Today, a substantial change has occurred, that is, be cited or unrecognized! Therefore, the growing citation neurosis has given rise to the pursuit of impact factor improvement. This obsession has not contaminated only researchers, but also editors. This happened because in Brazil, from 2009 on, CAPES (Coordination for the Improvement of Higher Education Personnel), through the new Qualis, established classification strata for Brazilian and foreign journals, imposing to some extent upon graduate programs the urgent necessity of trying to publish first in journals of high strata. The new Qualis classification is based on the impact factor annually published by the Journal Citation Reports (JCR) of the Thomson Scientific.

On the other hand, international journals not indexed by the JCR are broadcasting such things as unofficial IMPACT FACTOR $\mathbf{4 . 5}$ (this is the real difference among font sizes that appear on the official sites of these journals) as an "estimate". IIIadvised researchers access the chosen journal site, take a rapid look at the impact factor, which is usually at the top of the homepage, and, then, submit their papers. Belatedly, they learn from the CAPES ranking that the journal was not indexed by JCR so that this impact factor has no official value forward improving graduate program ratings.

Thus, we provide herein a warning to researchers in general: control the velocity neurosis and save some time to analyze the JCR homepage before submitting a paper to any scientific journal.

\section{CORRESPONDENCE TO:}

BENEDITO BARRAVIERA, Centro de Estudos de Venenos e Animais Peçonhentos, CEVAP, UNESP, Fazenda Experimental Lageado, Caixa Postal 577, Botucatu, SP, 18.618-000, Brasil. Phone: +55 143811 7241. Fax: +55 143814 5555. Email: bbviera@jvat.org.br. 